\title{
Exigências de Metionina + Cistina para Frangos de Corte Machos de 1 a 21 e de 22 a 42 Dias de Idade, em Clima Tropical ${ }^{1}$
}

\author{
René Geraldo Cordeiro Silva Junior², Geraldo Roberto Quintão Lana ${ }^{3}$, Carlos Boa-Viagem \\ Rabello ${ }^{4}$, Walter Amaral Barboza ${ }^{5}$, Sandra Roselí Valerio Lana ${ }^{3}$
}

\begin{abstract}
RESUMO - Foram realizados dois experimentos para determinação das exigências nutricionais de metionina + cistina total para frangos de corte machos da marca comercial Ross nos períodos de 1 a 21 e de 22 a 42 dias de idade, criados em clima tropical. Avaliaram-se o consumo de ração, o ganho de peso, a conversão alimentar, os pesos absolutos e os rendimentos de carcaça, de cortes nobres (peito, coxas e sobrecoxas) e de gordura abdominal. O delineamento adotado foi o inteiramente casualizado, com seis níveis de metionina + cistina, quatro repetições e 12 animais por unidade experimental, totalizando 288 aves em cada experimento. As rações foram calculadas para atenderem às exigências nutricionais das aves, à exceção dos níveis de metionina + cistina. As dietas foram suplementadas com DL-metionina nos níveis de 0; 0,08; 0,16; 0,24; 0,32 e 0,40\%, resultando em rações experimentais com 0,69; 0,77; 0,85; 0,93; 1,01 e 1,09\% de metionina + cistina, para o período de 1 a 21 dias, e 0,61; 0,69; 0,77; 0,85; 0,93 e 1,01\%, para o período de 22 a 42 dias de idade. Os níveis de metionina + cistina influenciaram de forma quadrática o ganho de peso e a conversão alimentar, no período de 1 a 21 dias, e o consumo de ração, o ganho de peso, a conversão alimentar, os pesos absolutos de carcaça e de peito e os rendimentos de carcaça, coxa e sobrecoxa no período de 22 a 42 dias de idade. De acordo com os resultados de desempenho produtivo, as exigências nutricionais de metionina + cistina para frangos de corte machos da marca comercial Ross foram estimadas em 0,96 e 0,89\%, para os períodos de 1 a 21 e de 22 a 42 dias de idade, respectivamente.
\end{abstract}

Palavras-chave: avaliação de carcaça, desempenho, exigência nutricional, frango de corte, metionina + cistina

\section{Requirements of Methionine + Cystine for Male Broilers from 1 to 21 and 22 to 42 Days Old on Climate Region}

\begin{abstract}
Two experiments were conducted to determine the nutritional requirements of total methionine + cystine for Ross male broilers from 1 to 21 and 22 to 42 days old on tropical climate. The following parameters were evaluated: feed intake, weight gain, feed:gain ratio and absolute weights and yields of carcass, noble cuts (chest, thighs and drumsticks) and abdominal fat. The experiment was analyzed as a complete randomized design with six levels of methionine + cystine and four replicates of 12 animals, in a total of 288 birds for each experiment. The diets were formulated to meet the bird nutricional requirements, except for methionine + cystine levels. The diets were supplemented with DL-methionine at levels of $0,0.08,0.16,0.24,0.32$, and $0.40 \%$, resulting in experimental diets with $0.69,0.77,0.85,0.93,1.01$ and $1.09 \%$ of methionine + cystine, for the period from 1 to 21 daysold and 0.61, 0.69, 0.77, 0.85, 0.93, and $1.01 \%$ of methionine + cystine, for the period from 22 to 42 days old. Quadratic effects of methionine + cystine levels on weight gain and feed:gain ratio, from 1 to 21 days old, and on feed intake, weight gain, feed:gain ratio, absolute weights of carcass and chest and yields of carcass, thighs and drumsticks, from 22 to 42 days old, were observed. According to the performance data, the nutritional requirements of methionine + cystine for male Ross broilers were estimated in 0.96 and $0.89 \%$ from 1 to 21 and 22 to 42 days old, respectively.
\end{abstract}

Key Words: broiler, methionine + cystine, nutritional requirement, performance, quality of carcass

\section{Introdução}

O sucesso da avicultura de corte é decorrente, em grande parte, da nutrição. Nos últimos 20 anos, o ganho de peso médio diário passou de 20 para mais de $50 \mathrm{~g} /$ dia e e a idade de abate reduziu de 12 para 6 semanas. Esta rapidez no desenvolvimento corporal tem demandado novas pesquisas sobre a real exigência de aminoácidos, sobretudo os sulfurosos.
Juntamente com estes avanços, trabalhos têm sido realizados com o objetivo de minimizar o desbalanceamento entre os nutrientes da ração. É recomendável manter uma relação entre os aminoácidos para se evitar a perda energética da dieta, resultante do desbalanceamento entre os aminoácidos. Além disso, a prática de se acrescentar aminoácidos sintéticos nas rações ocorre com freqüência em razão da facilidade de compra, dos preços

\footnotetext{
${ }^{1}$ Parte da tese do primeiro autor como exigência para obtenção do título de Doctor Scientiae.

${ }^{2}$ Professor Adjunto do curso de Zootecnia - UNIVASF, Petrolina - PE (rene.cordeiro@univasf.edu.br).

3 Professor Adjunto do Depto de Zootecnia - UFAL, Maceió - AL (glana@ceca.ufal.br; svlana@ceca.ufal.br).

${ }^{4}$ Professor Adjunto do Depto de Zootecnia - UFRPE, Recife - PE (cbviagem@ufrpe.br).

${ }^{5}$ Professor Adjunto do curso de Zootecnia - CCA - UFES, Alegre - ES (barbozawa@hotmail.com).
} 
compatíveis e dos altos custos das fontes protéicas da ração. Este fato tem possibilitado a obtençao de rações de mínimo custo, com teores de proteína bruta inferiores aos recomendados nas tabelas de exigências nutricionais, atendendo às exigências em aminoácidos essenciais para frangos de corte (Silva, 1996).

Segundo Albino et al. (1999), como os aminoácidos sulfurosos são utilizados em grandes quantidades pelas aves durante o período de crescimento corporal e são freqüentemente os primeiros limitantes em rações para frangos de corte, estas rações devem ser suplementadas com aminoácidos sintéticos, disponíveis no mercado.

Edmonds \& Baker (1987), ao trabalharem com frangos de corte machos no período de 1 a 21 dias de idade, verificaram que o excesso de $4 \%$ de metionina em ração à base de milho e farelo de soja reduziu o ganho de peso das aves.

Baker et al. (1982) forneceram ração basal purificada, contendo $0,40 \%$ de metionina +cistina, suplementada com cinco níveis de DL-metionina ( 0,05 ; 0,$10 ; 0,15 ; 0,20$ e 0,25\%) para pintos machos de 8 a 18 dias de idade e verificaram que as aves responderam de forma quadrática à suplementação de metionina, destacando-se que os níveis de 0,50 e $0,55 \%$ de metionina + cistina maximizaram o desempenho. Esses autores avaliaram, no entanto, ração padrão, à base de milho e farelo de soja, contendo $0,77 \%$ de metionina + cistina, suplementada ou não com quatro níveis crescentes de DL-metionina em incrementos de $0,05 \%$, e constataram que o desempenho foi maximizado com o nível de $0,869 \%$.

Resende et al. (1980a,bc) testaram rações contendo diferentes níveis de proteína bruta para frangos de corte machos nas fases de 1 a 28(I) e de 29 a 42 dias de idade (II), suplementadas com cinco níveis de DL-metionina $(0 ; 0,05 ; 0,10 ; 0,15$ e $0,20 \%)$ e não encontraram diferença no ganho de peso, durante a fase I, entre as aves alimentadas com rações que possuíam 21,5 e 20\% de proteína bruta, contendo, respectivamente, 0,74 e $0,71 \%$ de metionina + cistina, e aquelas que receberam ração controle. Durante a fase II, a exigência em metionina + cistina para ótimo ganho de peso das aves alimentadas com rações contendo $18 \%$ de proteína bruta foi de $0,65 \%$ e de $0,72 \%$ para aquelas que receberam rações contendo $16 \%$ de proteína bruta.

O objetivo neste trabalho foi determinar as exigências de metionina + cistina total para frangos de corte machos da marca comercial Ross nos períodos de 1 a 21 e 22 a 42 dias de idade.

\section{Material e Métodos}

Foram realizados dois experimentos, nos períodos de 09 a 30 de março e de 17 de junho a 08 de julho de 2004, no Setor de Avicultura do Departamento de Zootecnia da Universidade Federal Rural de Pernambuco - UFRPE, em Recife, PE.

O município de Recife está localizado na região litorânea do estado, a 4,5 m ao nível do mar e possui umidade relativa do ar entre 72 e $86 \%$.

As temperaturas máximas e mínimas no período experimental foram obtidas diariamente por meio de dois termômetros localizados em pontos médios do galpão a altura das aves (Tabela 1). A umidade relativa do ar no interior do galpão foi registrada por um termohigrômetro, obtendo-se médias de 80,8 e $81,4 \%$, durante o primeiro e o segundo período experimental, respectivamente.

Os experimentos foram conduzidos em galpão de alvenaria (20,00 m de comprimento, 6,65 m de largura e pé-direito de $2,80 \mathrm{~m}$ ) com telhado de cimento amianto, piso cimentado e paredes laterais de $0,80 \mathrm{~m}$ de altura, completadas com telas de arame 18.

O galpão foi diividido em 28 boxes de 1,00 x 1,95 m cada um, equipados com comedouros tubulares e bebedouros tipo pressão, que foram substituídos por bebedouros pendulares após o décimo dia experimental.

Em cada box foi instalado um círculo de proteção, constituído de uma folha de eucatex e uma lâmpada incandescente de $150 \mathrm{w}$ como fonte de calor, mantidos até o décimo dia de vida das aves. Durante esse período, o controle da temperatura foi realizado regulando-se a altura das lâmpadas e pelo manejo de cortinas, mantendo-se a temperatura em aproximadamente $32^{\circ} \mathrm{C}$.

Em cada experimento, foram utilizados 288 pintos de corte machos da marca comercial Ross, vacinados contra as doenças de Marek e Newcastle.

Os pesos médios iniciais das aves, para o primeiro e segundo experimentos, foram de 49,2 e 896,15 g, respectivamente.

As aves foram criadas sobre cama de maravalha. Foram instaladas em volta do galpão cortinas de polietileno trançado com a finalidade de oferecer às aves maior conforto.

As rações experimentais do primeiro e segundo experimentos, formuladas conforme as exigências nutricionais preconizadas por Rostagno et al. (2000), à exceção dos níveis de metionina + cistina, foram suplementadas com os níveis de $0 ; 0,08 ; 0,16 ; 0,24$; 0,32 e $0,40 \%$ de DL-metionina em substituição ao 
Tabela 1 - Médias da temperatura ambiente durante os períodos experimentais Table 1 - Averages of the environment temperature during the experimental periods

Período (dias)

Period (days)

Temperatura $\left({ }^{\circ} \mathrm{C}\right)$

Temperature

\begin{tabular}{|c|c|c|c|c|c|}
\hline & $\begin{array}{l}\text { Máxima } \\
\text { Highest }\end{array}$ & $\begin{array}{l}\text { Mínima } \\
\text { Lowest }\end{array}$ & $\begin{array}{c}\text { 9:00 } \\
\text { 9:00 a.m. }\end{array}$ & $\begin{array}{c}\text { 21:00 } \\
\text { 9:00 p.m. }\end{array}$ & $\begin{array}{l}\text { Média }^{1} \\
\text { Average }\end{array}$ \\
\hline $1-7$ & 32,4 & 29,2 & 30,3 & 28,1 & 29,6 \\
\hline $15-21$ & 30,6 & 27,8 & 29,4 & 27,7 & 28,6 \\
\hline $1-21$ & 31,2 & 28,3 & 29,5 & 27,9 & 29,0 \\
\hline $22-28$ & 31,5 & 28,8 & 30,0 & 27,6 & 29,1 \\
\hline 36-42 & 30,2 & 28,1 & 30,2 & 27,1 & 28,5 \\
\hline $22-42$ & 30,6 & 28,5 & 29,9 & 27,6 & 28,8 \\
\hline
\end{tabular}

${ }^{1}$ Calculadas de acordo com o controle do Instituto Nacional de Meteorologia (INMET Brasília-DF) pela fórmula: (T9h+Tmín.+Tmax.+2.T21h)/ 5 , utilizando-se os registros de temperatura às $9 \mathrm{~h}(\mathrm{~T} 9 \mathrm{~h})$, temperatura mínima (Tmin.), temperatura máxima (Tmáx.) e temperatura às $21 \mathrm{~h}(\mathrm{~T} 21 \mathrm{~h})$.

${ }^{1}$ Calculated according to the control of National Institute of Meteorology (INMET Brasilia - DF) according to the following formula $=(T 9 h+T m i ́ n .+T m a x .+2 . T 21 h) /$ 5, using data of temperature at 9 a.m. (T9h), lowest temperature (Tmin.), highest temperature (Tmax.) and temperature at 9 p.m. (T21h).

inerte, resultando em rações experimentais com 0,69 ; 0,77; 0,85; 0,93; 1,01 e 1,09\% de metionina + cistina, para o período de 1 a 21 dias de idade, e 0,$61 ; 0,69$; 0,77; 0,85; 0,93 e $1,01 \%$, para o período de 22 a 42 dias de idade (Tabela 2).

As rações foram fornecidas à vontade. No período de 1 a 21 dias, as aves do segundo experimento foram alimentadas com ração contendo 21,4\% de proteína bruta, $3.000 \mathrm{kcal}$ de EM/kg e 0,89\% de metionina + cistina.

Foram avaliados o consumo de ração, o ganho de peso, a conversão alimentar (primeiro e segundo experimento) e os pesos absolutos e relativos de carcaça, cortes nobres (peito, coxas e sobrecoxas) e gordura abdominal (segundo experimento).

Para avaliação da carcaça, no segundo experimento, foram abatidas duas aves por unidade experimental, aos 42 dias de idade. Após jejum de 6 horas, as aves foram pesadas, abatidas, depenadas, evisceradas e pesadas novamente, sem pés, cabeça e pescoço, para cálculo do rendimento de carcaça em relação ao peso vivo em jejum. Os rendimentos de cortes nobres (peito, coxas e sobrecoxas) e gordura abdominal foram estimados em relação ao peso da carcaça eviscerada.

O delineamento experimental foi o inteiramente casualizado, com seis níveis de metionina + cistina, quatro repetições e 12 aves por unidade experimental.

As análises estatísticas das variáveis estudadas foram utilizando-se o programa SAEG (Sistema para Análises Estatísticas), Versão 8.0 (UFV, 2001). As estimativas de exigências de metionina + cistina para frangos de corte de 1 a 21 e de 22 a 42 dias de idade foram estabelecidas com base nos resultados de desempenho produtivo, por modelos de regressões linear e quadrática, conforme o melhor ajuste obtido para cada variável.

\section{Resultados e Discussão}

Os resultados do desempenho produtivo das aves, obtidos no período de 1 a 21 dias de idade (primeiro experimento), encontram-se na Tabela 3.

O efeito dos níveis de metionina + cistina sobre o consumo de ração não foi significativo ( $\mathrm{P}>0,05)$, o que está de acordo com o resultado encontrado por Silva (1996), queutilizou diferentes níveis de metionina + cistina em rações com 20\% de proteína bruta e 3.100 kcal EM/kg. Wheeler \& Latshaw (1981), no entanto, relataram que o aumento dos níveis de metionina + cistina favoreceu a diminuição do consumo de ração das aves. Segundo Waldroup et al. (1976), níveis de inclusão de aminoácidos acima das exigências para frangos de corte promovem efeito redutor no consumo de ração.

Os níveis de metionina + cistina influenciaram de forma quadrática $(\mathrm{P}<0,05)$ o ganho de peso (Figura 1$)$, estimando-se, pela equação de regressão: $\hat{Y}=-330,94+2496,18 X-1299,34 X^{2}\left(R^{2}=0,83\right)$, o nível de $0,96 \%$ para o maior ganho de peso das aves $(870,00 \mathrm{~g})$.

Este nível foi superior aos obtidos por Albino et al. (1999) e Oliveira (2000), de 0,91 e 0,86\%, respectivamente, que também estudaram o efeito de níveis de metionina + cistina para frangos de corte machos da marca comercial Ross no período de 1 a 21 dias de idade. Quando os níveis de metionina + cistina se 
Tabela 2 - Composição percentual da ração basal Table 2 - Ingredient composition (\%) of basal diet

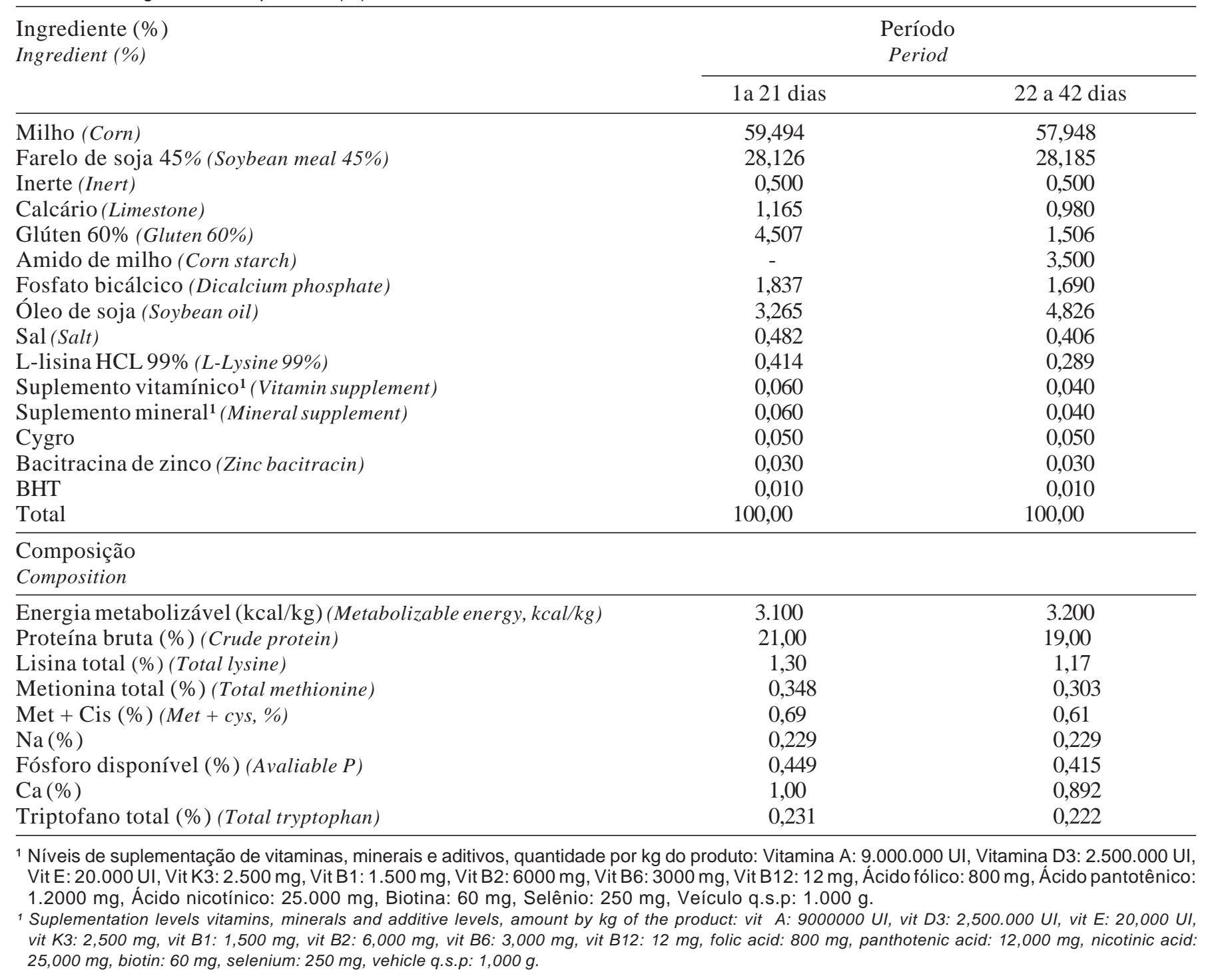

situaram acima da exigência estabelecida, não houve resposta satisfatória no ganho de peso, diferindo das observações de Han \& Baker (1993), de que o excesso de metionina + cistina na ração não influenciou negativamente os resultados de ganho de peso de frangos de corte no período de 1 a 21 dias de idade.

Os piores resultados para ganho de peso, observados nas aves alimentadas com ração contendo níveis inferiores ao estabelecido, provavelmente foram conseqüência do desbalanço de aminoácidos, causado pela deficiência de metionina.

Observou-se efeito quadrático $(\mathrm{P}<0,05)$ dos níveis de metionina + cistina sobre a conversão alimentar (Figura 2). Utilizando-se a equação de regressão, $\hat{\mathrm{Y}}=3,51-4,68 \mathrm{X}+2,52 \mathrm{X}^{2}\left(\mathrm{R}^{2}=0,85\right)$, estimou-se o nível de $0,93 \%$ para melhor conversão alimentar.
Os resultados indicaram melhoria da conversão alimentar à medida que os níveis de metionina + cistina se aproximaram da exigência e piora gradativa quando estes níveis foram elevados a 1,01 e 1,09\% (Tabela 3), comprovando a importância da manutenção do equilíbrio aminoacídico das dietas, uma vez que o excesso de aminoácidos nas rações altera significativamente o metabolismo das aves.

É importante salientar que, quando o frango de corte ingere uma dieta deficiente em metionina + cistina, a síntese protéica torna-se limitada, resultando em ineficiente utilização dos demais aminoácidos. Por isso, é provável que aves alimentadas com essas dietas apresentem altas concentrações de ácido úrico na corrente sangüínea (Baker, 1991). 
Exigências de Metionina + Cistina para Frangos de Corte Machos de 1 a 21 e de 22 a 42 Dias de Idade...

Tabela 3 - Desempenho produtivo de frangos de corte de 1 a 21 dias de idade alimentados com rações contendo diferentes níveis de met + cis (\%)

Table 3 - Performance of broilers fed diets with different met + cys levels (\%) from 1 to 21 days old

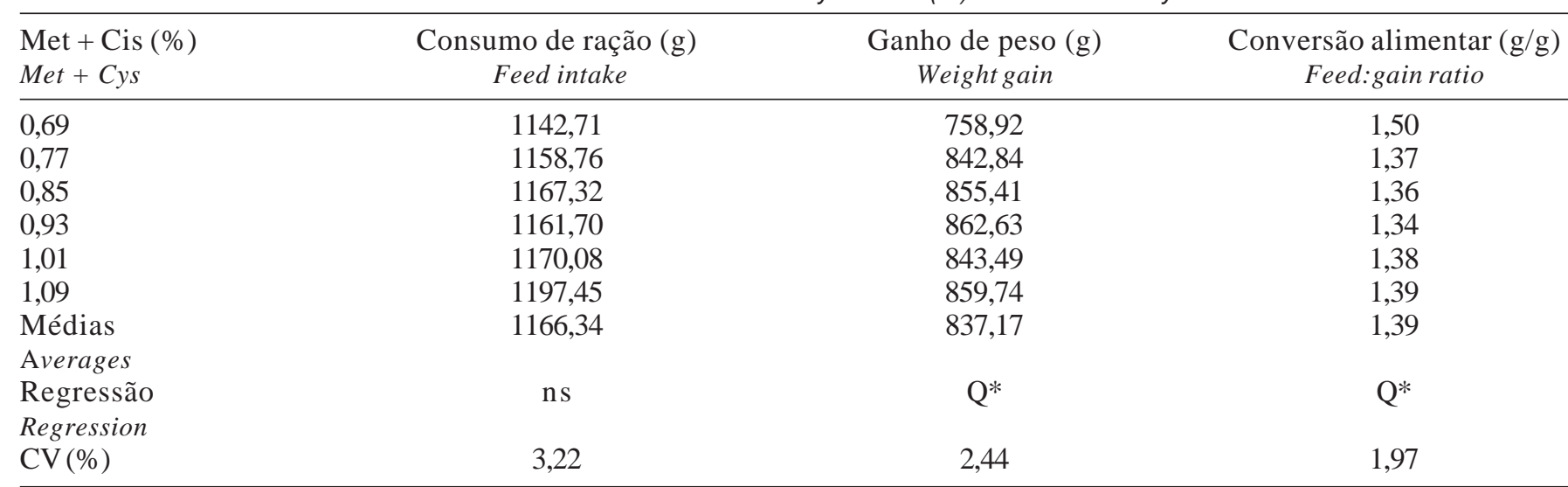

$\mathrm{Q}=$ Quadrática (Quadratic); ns = não-significativo (not significant); * Significativo $(\mathrm{P}<0,05)$ (Significant).

Na Tabela 4 encontram-se os resultados do desempenho produtivo de frangos de corte, obtidos no período de 22 a 42 dias de idade, de acordo com os níveis de metionina + cistina (met + cis).

Houve efeito significativo $(\mathrm{P}<0,05)$ dos níveis de metionina + cistina sobre o consumo de ração das aves, observando-se diminuição no consumo à medida que se elevaram os níveis de metionina + cistina. As aves apresentaram maiorconsumo de ração (3582,80 g) com o nível de $0,6 \%$ e o menor (3446,75 g), com 1,01\% de metionina + cistina.

Verificou-se efeito quadrático $(\mathrm{P}<0,05)$ dos níveis de metionina + cistina sobre o consumo de ração

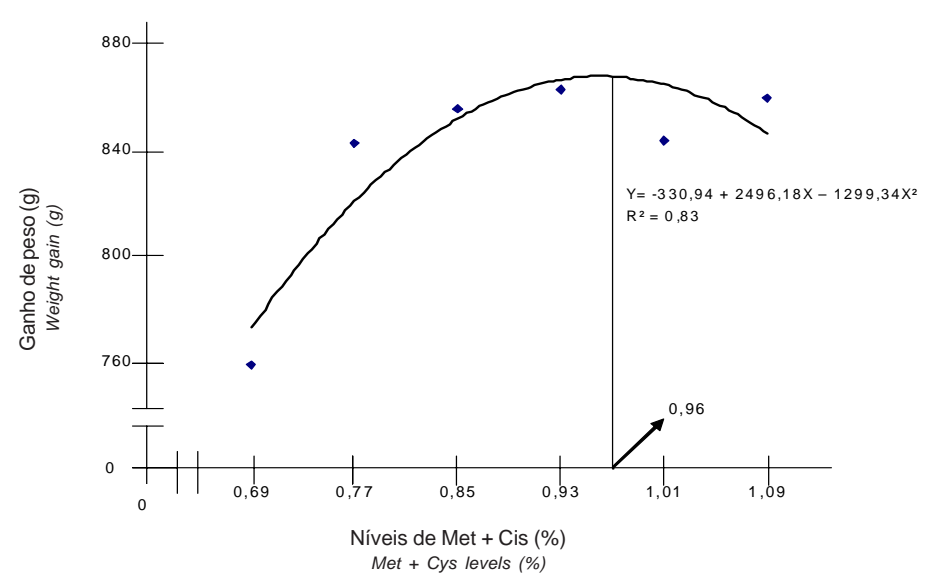

Figura 1- Ganho de peso, de acordo com os níveis de met + cis (\%), no período de 1 a 21 dias de idade.

Figure 1 - Weigth gain according to met + cys (\%) levels in the period from 1 to 21 days old.
(Figura 3), conforme obsevado também por Wheeler \& Latshaw (1981) e Rodrigueiro et al. (2000), que relataram em seus estudos que a elevação dos níveis de metionina + cistina favoreceram o aumento do peso corporal e a redução do consumo de ração das aves. Segundo Waldroup et al. (1976), níveis de inclusão de aminoácidos acima das exigências estabelecidas para frangos de corte causam efeito redutor no consumo de ração.

Uma vez que as rações neste experimento (à base de milho e farelo de soja) foram isoenergéticas e isoprotéicas, o menor ganho de peso das aves, associado ao maior consumo de ração, indicou que a

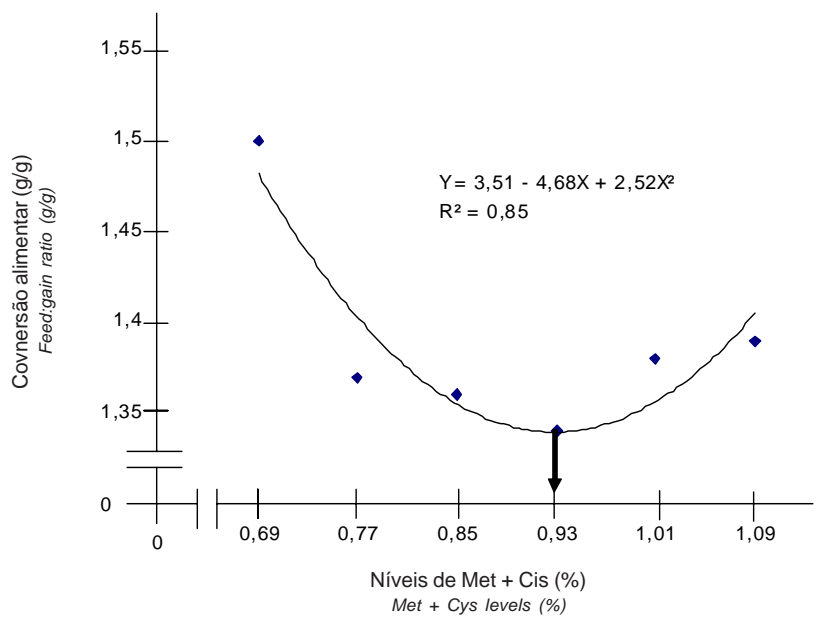

Figura 2 - Conversão alimentar, de acordo com os níveis de met + cis (\%), no período de 1 a 21 dias de idade.

Figure 2 - Feed: gain ratio according to met + cys (\%) levels in the period from 1 to 21 days old. 
metionina foi o aminoácido limitantenaração, diminuindo a síntese de proteína corporal. Esses resultados comprovam o fato de que o consumo de ração pelas aves não é dependente apenas da teoria glicostática, sendo influenciado também pelos níveis de aminoácidos essenciais na ração.

Os resultados obtidos neste trabalho são contraditórios, no entanto, aos reportados por Silva (1996), que, utilizando rações contendo $20 \%$ de proteína bruta e $3100 \mathrm{kcal}$ de EM/kg, demonstrou não haver efeito dos níveis de metionina + cistina sobre o consumo de ração. Resultados semelhantes também foram relatados por Atencio et al. (2004), em estudo com frangos de corte machos no período de 24 a 38 dias de idade recebendo níveis de 0,67 a 0,83\% de metionina + cistina na ração.

Os níveis de metionina + cistina influenciaram de forma quadrática $(\mathrm{P}<0,05)$ no ganho de peso (Figura 4 ), de modo que o nível de $0,89 \%$ foi que maximizou essa variável.

A estimativa da exigência para ganho de peso neste experimento foi superior aos níveis de 0,82 e $0,84 \%$, obtidos por Albino et al. (1999) e Atencio et al. (2004), respectivamente, que também estudaram o efeito de níveis de metionina + cistina para frangos de corte machos da marca comercial Ross no período de 22 a 42 dias de idade. Neste trabalho, quando os níveis de metionina + cistina ficaram acima da exigência estabelecida, não houve resposta eficiente no ganho de peso das aves, o que contraria as observações de Atencio et al. (2004), Jensen et al. (1989) e Schutte \& Pack (1995), que constataram em seus estudos que o aumento dos níveis de metionina + cistina na ração não influenciaram negativamente o ganho de peso de frangos de corte no período de 22 a 42 dias de idade.

Os piores resultados para a variável ganho de peso foram observados nas aves alimentadas com ração contendo níveis inferiores a 0,85\% de metionina + cistina, provavelmente em conseqüência do desbalanço de aminoácidos (Albino et al., 1999).

Observou-se também efeito quadrático $(\mathrm{P}<0,05)$ dos níveis de metionina + cistina na ração sobre a conversão alimentar, estimando-se o nível de 0,90\%, para essa variável (Figura 5). Este resultado é similar ao registrado por Rodrigueiro et al. (2000) e Shutte \& Pack (1995), de 0,88\%, e inferior ao descrito por Albino et al. (1999), de 0,92\%, em trabalho realizado com frangos de corte machos Ross no período de 22 a 42 dias de idade.

O valor da exigência para melhor conversão alimentar foi superior àquele para ganho de peso, o que está de acordo com as informações de Resende et al. (1980b), Skinner et al. (1992) e Shutte \& Pack (1995), que também encontraram maior exigência para a conversão alimentar que para ganho de peso.

Acima da exigência estabelecida, o desempenho não apresentou melhoria, provavelmente em razão do excesso de aminoácidos, que prejudicou o consumo. Esses dados divergem dos obtidos por Waldroup et al. (1976), que verificaram melhoria no ganho de peso e na conversão com aumento dos níveis de metionina + cistina na ração.

Tabela 4 - Desempenho produtivo de frangos de corte de 22 a 42 dias de idade submetidos a diferentes níveis de met + cis (\%) na ração

Table 4 - Performance of broilers fed diets with different met + cys (\%) levels from 22 to 42 days old

\begin{tabular}{lccc}
\hline $\begin{array}{l}\text { Met + Cis (\%) } \\
\text { Met + Cys }\end{array}$ & $\begin{array}{c}\text { Consumo de ração (g) } \\
\text { Feed intake }\end{array}$ & $\begin{array}{c}\text { Ganho de peso (g) } \\
\text { Weight gain }\end{array}$ & $\begin{array}{c}\text { Conversão alimentar (g/g) } \\
\text { Feed:gain ratio }\end{array}$ \\
\hline 0,61 & 3582,80 & 1771,87 & 2,02 \\
0,69 & 3530,30 & 1846,18 & 1,91 \\
0,77 & 3462,49 & 1857,08 & 1,86 \\
0,85 & 3449,16 & 1907,81 & 1,80 \\
0,93 & 3532,49 & 1873,12 & 1,88 \\
1,01 & 3446,75 & 1881,87 & 1,83 \\
Médias & 3500,66 & 1856,32 & 1,88 \\
Averages & & & $\mathrm{Q}^{*}$ \\
Regressão & $\mathrm{Q}^{*}$ & & 0,71 \\
Regression & & 0,90 &
\end{tabular}

$\mathrm{Q}=$ Quadrática (Quadratic); ns = não-significativo (not significant); * Significativo $(\mathrm{P}<0,05)$ (Significant). 


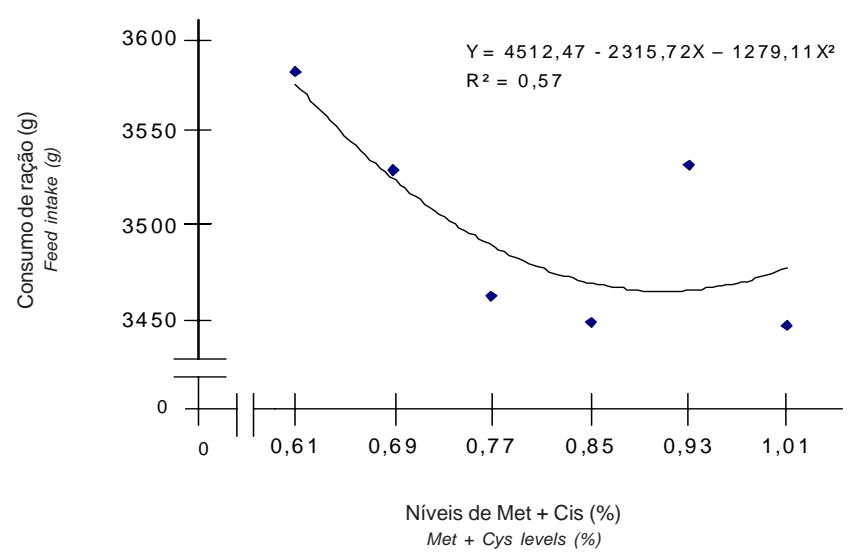

Figura 3 - Consumo de ração, de acordo com os níveis de met + cis (\%) na ração, no período de 22 a 42 dias de idade.

Figure 3 - Feed intake according to met + cis (\%) levels in the period from 22 to 42 days old.

Constam na Tabela 5 os resultados de pesos absolutos e de rendimentos de carcaça, peito, coxa, sobrecoxa e gordura abdominal de frangos de corte aos 42 dias de idade, de acordo com os níveis de metionina + cistina (met + cis) na ração.

Houve efeito quadrático $(\mathrm{P}<0,05)$ dos níveis de metionina + cistina sobre o peso absoluto de carcaça, estimando-se exigência de $0,91 \%$, conforme equação $\hat{Y}=-486,37+5159 X-2836,57 X^{2}\left(R^{2}=0,89\right)$. Este resultado se assemelha ao reportado por Silva (1996), ao utilizarem rações com $20 \%$ de proteína bruta e níveis de 0,64 a 0,94\% de metionina + cistina.

Foi verificado efeito quadrático $(\mathrm{P}<0,05)$ sobre o rendimento da carcaça, de acordo com a equação $\hat{Y}=-0,13+151,86 X-82,07 X^{2}\left(R^{2}=0,85\right)$, estimando-se em $0,92 \%$ a exigência de metionina + cistina, como relatado por Moran Jr. (1994) e Rodrigueiro et al. (2000), que verificaram em seus trabalhos efeito dos níveis de metionina + cistina sobre o rendimento de carcaça. Resultados contrários, no entanto, foram relatados por Atencio et al. (2004), que não observaram efeito significativo dos níveis de metionina + cistina sobre o rendimento de carcaça de frangos de corte no período de 24 a 38 dias de idade. Barbosa (2000), em frangos de corte machos de 22 a 42 dias de idade, registrou efeito linear aumento dos níveis de metionina + cistina na ração sobre o rendimento de carcaça das aves.

Os níveis de metionina + cistina influenciaram de forma quadrática $(\mathrm{P}<0,05)$ o peso absoluto de peito,

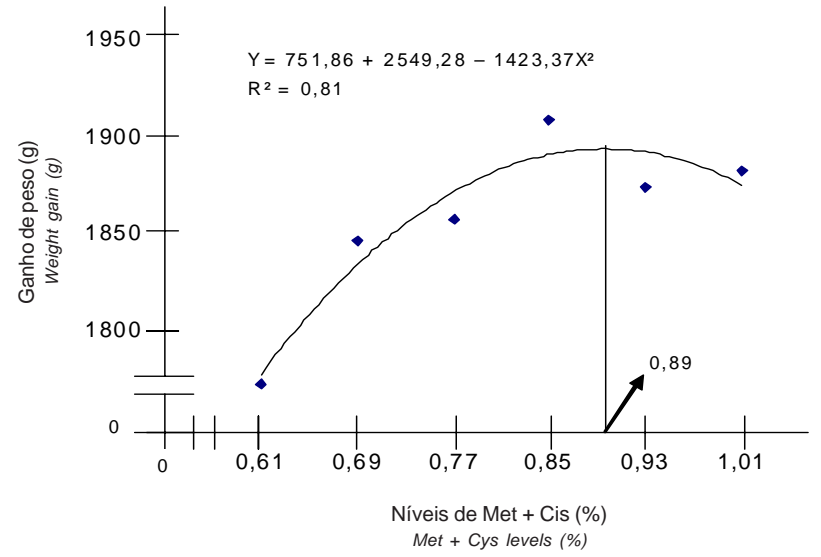

Figura 4 - Ganho de peso, de acordo com os níveis de met + cis (\%) na ração, no período de 22 a 42 dias de idade.

Figure 4 - Weigth gain according to met + cys (\%) levels in the period from 22 to 42 days old.

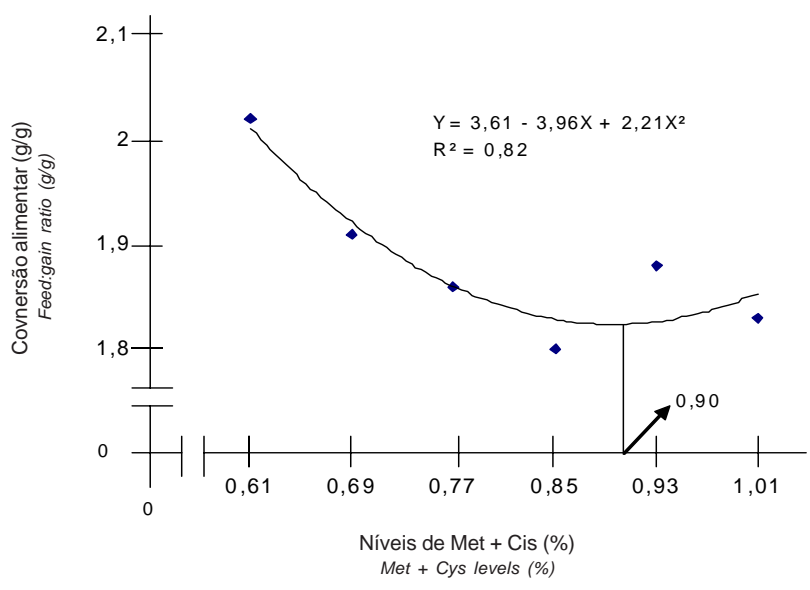

Figura 5 - Conversão alimentar, de acordo com os níveis de met + cis (\%) na ração, no período de 22 a 42 dias de idade.

Figure 5 - Feed: gain ratio according to met + cis (\%) levels in the period from 22 to 42 days old.

estimando-se a exigência em $0,90 \%$, conforme equação: $\hat{Y}=-225,17+2007,95 X-1118,51 X^{2}\left(R^{2}=0,94\right)$. Silva (1996) também notou efeito quadrático do nível de $0,88 \%$ de inclusão de metionina + cistina na ração sobre o peso absoluto de peito das aves, no mesmo período de criação (22 a 42 dias de idade).

Não houve efeito significativo $(\mathrm{P}>0,05)$ dos níveis de metionina + cistina sobre o rendimento de peito das aves, o que está de acordo com os níveis descritos por Barbosa (2000) e Atencio et al. (2004), de 0,67 a $0,83 \%$ de metionina + cistina para o mesmo período de criação. Observações contrárias foram relatadas por 
Moran Jr. (1994) e Rodrigueiro et al. (2000), que verificaram efeito quadrático $(\mathrm{P}<0,05)$ sobre o rendimento de peito, com exigências estimadas em 0,83 e 0,82\% de metionina + cistina, respectivamente. Schutte \& Pack (1995) e Jeroch \& Pack (1995), por sua vez, recomendam inclusão de $0,88 \%$ de metionina + cistina para o melhor rendimento de peito das aves.

Os níveis de metionina + cistina influenciaram $(\mathrm{P}<0,05)$ os pesos absolutos de coxa, sobrecoxa e gordura abdominal. Porém, não foi possível o ajuste de equações para explicar esse fato. O maior peso absoluto de coxas $(269,93 \mathrm{~g})$ foi observado com o nível de 1,01\% de metionina + cistina, enquanto o de sobrecoxa (353,43 g) foi obtido com o nível de $0,69 \%$ de metionina + cistina. Os menores pesos de gordura abdominal foram verificados com os níveis de 0,93 e 1,01\% de metionina + cistina. Esses resultados são contrários aos relatados por Barbosa (2000), que não notou efeito dos níveis de metionina + cistina para essas variáveis.
Houve efeito quadrático $(\mathrm{P}<0,05)$ dos níveis de metionina + cistina sobre o rendimentos de coxa, conforme a equação, $\hat{Y}=32,97-41,85 X+23,41 X^{2}$ $\left(\mathrm{R}^{2}=0,71\right)$, estimando-se a exigência em $0,90 \%$, e de sobrecoxa, de acordo com a equação, $\hat{Y}=47,62-$ $66,81 X+37,66 X^{2}$, estimando-se a exigência de metionina + cistina em $0,89 \%$.

Foi observado efeito quadrático $(\mathrm{P}<0,05)$ dos níveis de metionina + cistina sobre o rendimento de gordura abdominal, conforme a equação, $\hat{Y}=10,20$ $19,22 X+10,87 X^{2}\left(R^{2}=0,83\right)$, estimando-se a exigência em $0,88 \%$. Albino et al. (1999) obtiveram em seus estudos menores deposições de gordura na carcaça nos níveis de 0,81 e 0,87\%, diferentemente de Rodrigueiro et al. (2000), que obtiveram menor deposição de gordura abdominal com níveis entre 0,87 e 0,93\% de metionina + cistina na ração.

Os maiores valores para rendimento de gordura abdominal encontrados nesta pesquisa podem estar

Tabela 5 - Efeitos de diferentes níveis de met + cis (\%) na ração sobre os pesos absolutos e rendimentos de carcaça, peito, coxa e sobrecoxa e gordura abdominal de frangos de corte aos 42 dias de idade

Table 5 - Effects of feeding diferent dietary levels of met + cys (\%) on absolute weights and yields of carcass, chest, thighs, drumsticks and abdominal fat of broilers at 42 days old

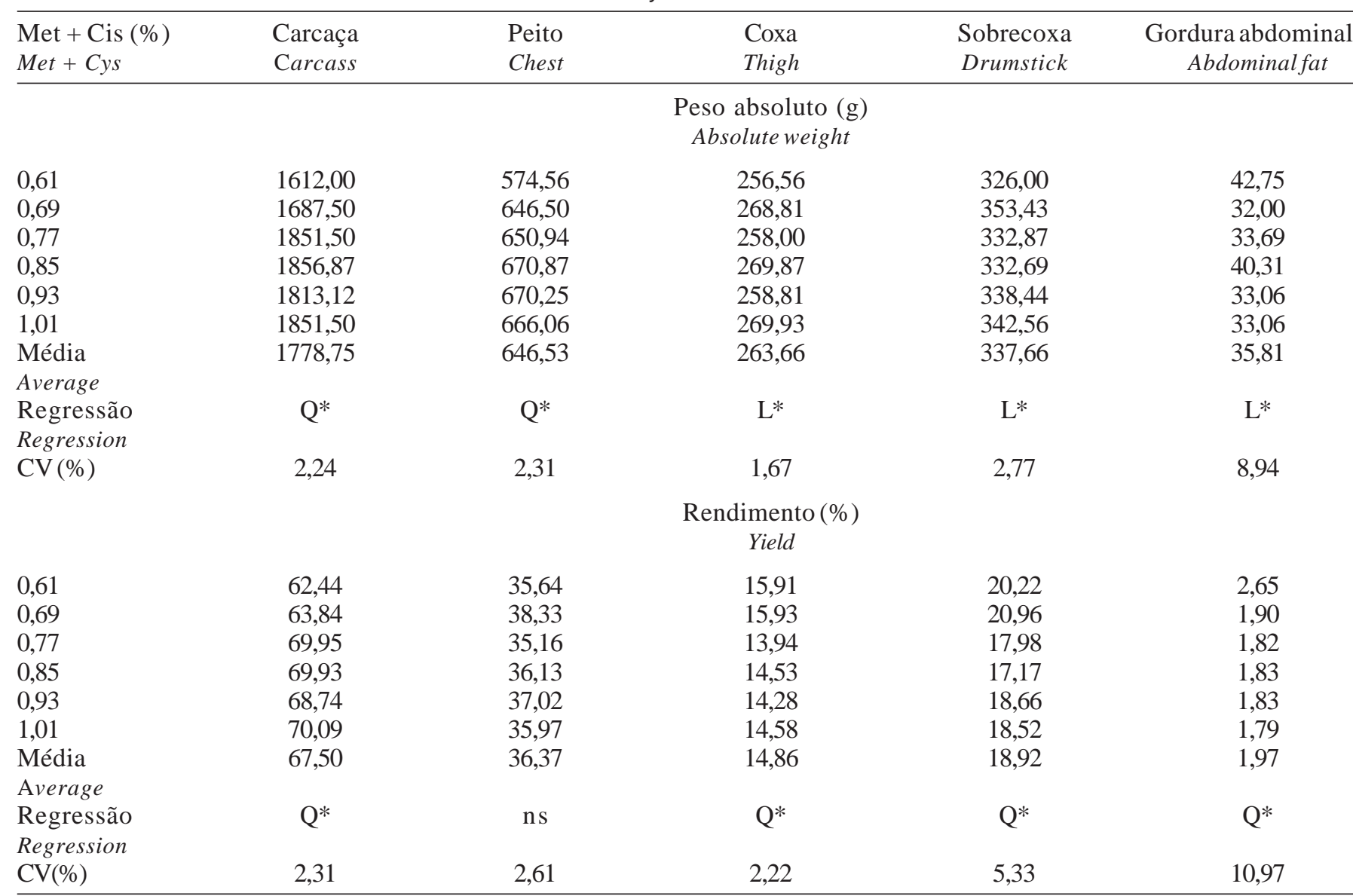

$\mathrm{Q}=$ Quadrática (Quadratic); ns = não-significativo (not significant); * Significativo $(\mathrm{P}<0,05)$ (Significant). 
relacionados ao desequilíbrio aminoacídico na ração. Esse desequilíbrio limita o acúmulo de tecido magro e direciona as calorias para os adipócitos, o que provavelmente pode ter ocorrido após o atendimento ao nível de exigência das aves.

\section{Conclusões}

De acordo com os resultados de desempenho produtivo e considerando-se o ganho de peso das aves, as exigências nutricionais de metionina + cistina para frangos de corte machos da marca comercial Ross foram de 0,96 e 0,89\%, para os períodos de 1 a 21 e de 22 a 42 dias de idade, respectivamente.

\section{Literatura Citada}

ALBINO, L.F.T.; SILVA, S.H.M.; VARGAS JR., J.G. et al. Níveis de metionina + cistina para frangos de corte de 1 a 21 e 22 a 42 dias de idade. Revista da Sociedade Brasileira de Zootecnia, v.28, n.3, p.519-525, 1999.

ATENCIO, A.; ALBINO, L.F.T.; ROSTAGNO, H.S. et al. Exigências de metionina + cistina para frangos de corte machos em diferentes fases de criação. Revista Brasileira de Zootecnia, v.33, n.5, p.1152-1166, 2004.

BAKER, D.H.; HALPIN, K.M.; CZAENECKI, G.L. et al. The choline-methionine interrelationship growth of the chick. Poultry Science, v.62, p.133-137, 1982.

BAKER, D.H. Partitioning of nutrients for growth and metabolic: functions. Poultry Science, v.70, p.1797-1805, 1991.

BARBOSA, M.J.B. Exigências nutricional de lisina e metionina + cistina para frangos de corte. Jaboticabal: Universidade Estadual Paulista, 2000. 93p. Tese (Doutorado em Zootecnia) - Universidade Estadual Paulista, 2000.

EDMONDS, M.S.; BAKER, D.H. Comparative effects of individual amino acid excesses when added to a corn-soybean meal diet: effects on growth and dietary choice in the chick. Journal of Animal Science, v.65, p.699-705, 1987.

HAN, Y.; BAKER, D.H. Effects of excess methionine or lysine for broilers fed a corn - soybean meal diet. Poultry Science, v.72, p.1070-1074, 1993.

JENSEN, L.S.; WIATT, C.L.; FANCHER, B.I. Sulfur amino acid requirement of broiler chikens from 3 to 6 weeks of age. Poultry Science, v.68, p.163-168, 1989.

JEROCH, H.; PACK, M. Effects of dietary sulfur amino acids and crud protein on the performance of finishing broilers. Archives of animal Nutrition, v.48, p.109-118, 1995.

MORAN, E.T.JR. Response of broiler strains differing in body fat to inadequate methionine: live performance and processing yields. Poultry Science, v.73, p.1116-1126, 1994.

OLIVEIRA, F.J.G. Níveis de metionina + cistina, em função do nível de proteína bruta da ração, para frangos de corte no período de um a 21 dias de idade. Recife: Universidade Federal Rural de Pernambuco, 2000. 61p. Dissertação (Mestrado em Zootecnia) - Universidade Federal Rural de Pernambuco, 2000.
RESENDE, J.A.A.; ROSTAGNO, H.S.; FONSECA, J.B. et al. Níveis de proteína, aminoácidos sulfurosos e lisina na ração de frangos, submetidos a regime de alta temperatura. I. fase inicial. Revista da Sociedade Brasileira de Zootecnia, v.1, p.90-107, 1980a.

RESENDE, J.A.A.; ROSTAGNO, H.S.; SILVA, M.A. et al. Níveis de proteína, aminoácidos sulfurosos e lisina na ração de frangos, submetidos a regime de alta temperatura. II. Fase crescimento. Revista da Sociedade Brasileira de Zootecnia, v.1, p.108-124, 1980b.

RESENDE, J.A.A.; ROSTAGNO, H.S.; FONSECA, J.B. et al. Níveis de proteína, aminoácidos sulfurosos e lisina na ração de frangos, submetidos a regime de alta temperatura. III. fase acabamento. Revista da Sociedade Brasileira de Zootecnia, v.1, p.125-141, 1980c.

RODRIGUEIRO, R.J.B.; ALBINO, L.F.T.; ROSTAGNO, H.S et al. Exigência de metionina + cistina para frangos de corte na fase de crescimento e acabamento. Revista Brasileira Zootecnia, v.29, n.2, p.507-517, 2000.

ROSTAGNO, H.S.; ALBINO, L.F.T.; DONZELE, J.L. et al. Tabelas brasileiras para aves e suínos: composição de alimentos e exigências nutricionais. Viçosa, MG: Universidade Federal de Viçosa, 2000. 141p.

SCHUTTE, J.B.; PACK, M. Sulfur amino acid requirement of broiler chicks from fourteen to thirty-eight days of age. 1 . performance and carcass yield. Poultry Science, v.74, n.3, p.480-487, 1995.

SILVA, M.A. Exigências nutricionais em metionina + cistina para frangos de corte, em função do nível de proteína bruta da ração. Viçosa, MG: Universidade Federal de Viçosa, 1996. 73p. Dissertação (Mestrado em Zootecnia) - Universidade Federal de Viçosa, 1996.

SKINNER, J.T.; WALDROUP, A.L.;WALDROUP, P.W. Effects of protein and amimo acid level fed zero to forty-two days on response of broiler to protein and aminoacidlevels fed forty-two to forty-nine days of age. Poultry Science, v.71, p.1350-1355, 1992.

UNIVERSIDADE FEDERAL DE VIÇOSA - UFV. SAEG Sistemas de análises estatísticas. Versão 8.0. Viçosa, MG: 2001. 150p. (Manual do usuário).

WALDROUP, P.W.; MITCHEL, R.J.; PAYNE, J.R. et al. Performance of chicks fed diets formulated to minimize excess levels of essential amino acids. Poultry Science, v.55, p.243-253, 1976.

WHEELER, K.B.; LATSHAW, J.D. Sulfur amino acid requirements and interactions in broilers during two growth periods. Poultry Science, v.60, p.228-236, 1981. 